\title{
Polymorphisms FTO rs9939609, PPARG rs1801282 and ADIPOQ rs4632532 and rs182052 but not lifestyle are associated with obesity related-traits in Mexican children
}

\author{
Muñoz-Yáñez $\mathrm{C}^{1}$, Pérez-Morales $\mathrm{R}^{2}$, Moreno-Macías $\mathrm{H}^{3}$, Calleros-Rincón E ${ }^{2}$, Ballesteros $\mathrm{G}^{4}$, González R.A ${ }^{4}$ \\ and Espinosa $\mathrm{J}^{1}$ \\ ${ }^{1}$ Departamento de Investigación, Facultad de Medicina, Universidad Juárez del Estado de Durango, \\ Durango, México. \\ ${ }^{2}$ Departamento de Biología Molecular, Facultad de Ciencias Químicas, Universidad Juárez del Estado de \\ Durango, Durango, México. \\ ${ }^{3}$ Departamento de Economía, División CSH de la Universidad Autónoma Metropolitana, Unidad Iztapalapa, \\ D.F. México, México. \\ ${ }^{4}$ Facultad de Ciencias, Universidad Autónoma del Estado de Morelos, Cuernavaca, Morelos, México.
}

\begin{abstract}
Concerning the genetic factors of obesity, no consistent association between populations has been reported, which may be due to the frequency of polymorphisms, the lifestyle of studied populations and its interaction with other factors. We studied a possible association of polymorphisms FTO rs9939609, PPARG rs1801282, and ADIPOQ rs4632532 and rs182052 with obesity phenotypes in 215 Mexican children. Glucose, triglycerides, cholesterol, HDL and LDL were measured. In addition, weight, height, waist circumference and triceps skin thickness were recorded. High-energy diets and sedentary behavior were evaluated with a validated questionnaire. In contrast with other reports, only FTO rs9939609 was associated with obesity related-traits, including $\mathrm{BMI}(p=0.03)$, waist circumference $(p=0.02)$, triceps skinfold $(p=0.03)$ and waist/height ratio $(p=0.01)$, and also with cholesterol levels $(p=0.02)$ and LDL $(p=0.009)$. Lower levels of triglycerides $(p=0.04)$ were related with presence of PPARG rs1801282, while $A D I P O Q$ rs4632532 showed an effect on $\operatorname{HDL}(p=0.03)$ levels. On the other hand, diet, physical activity and screen time were not related with obesity. In summary, only FTO rs9939609 was associated with obesity related-traits, while PPARG2 rs1801282 and ADIPOQ rs4632532 were involved in lipid metabolism.
\end{abstract}

Keywords: Obesity, children; polymorphisms, energy intake, physical activity, lipid profile.

Received: November 4, 2015; Accepted: February 29, 2016.

\section{Introduction}

Obesity is a worldwide public health problem due to its association with chronic diseases, such as type 2 diabetes, hypertension, cardiovascular disorders and certain types of cancer. Obesity results from an interaction of social, psychological, genetic and environmental factors, like diet and physical exercise. The last National Health and Nutrition Survey found that the national prevalence of childhood overweight did not increase. However, in the Mexican state of Durango the childhood obesity raised from $22.9 \%$ in 2006 (Shamah-Levy and Villalpando-Hernández, 2007) to $37.5 \%$ in 2012 (Rivero-Vázquez, 2013), which might be the result of different genetic backgrounds of Mexico's

Send correspondence to Jorge Espinosa. Facultad de Medicina, Universidad Juárez del Estado de Durango, Calz. Palmas 1 y Sixto Ugalde s/n. Col. Revolución. C.P. 35050 Gómez Palacio, Durango, Mexico. E-mail: dr.jorge.espinosa@gmail.com
Northern populations (Silva-Zolezzi et al., 2009). Many studies have demonstrated that genetic factors have an important role in the development of obesity, although results are different depending on the population being evaluated.

One of the most studied genes, the PPARG is a member of the nuclear hormone receptors super-family, which regulates transcription of genes involved in several biological functions, such as cell growth, adipocyte differentiation, metabolism of cholesterol and fatty acids, cell survival, ubiquitination and adaptive thermogenesis. PPARG is activated by lipophilic hormones, fatty acids from the diet, and their metabolites (He, 2009). The Ala allele of the polymorphism Pro12Ala of PPARG was associated with obesity in a population from Spain $(\mathrm{OR}=2.36, \mathrm{p}=0.03)$ and from India $(\mathrm{OR}=3.2, \mathrm{p}=0.02)$ (González-Sánchez et al., 2002; Bhatt et al., 2012), while the Pro allele was a risk factor for type 2 diabetes in a French population $(\mathrm{OR}=$ $1.37, \mathrm{p}=0.04$ ) (Ghoussaini et al., 2005). 
FTO was the first gene to be associated with obesity by genome-wide association studies (GWAs). Adults homozygous the A allele, in rs9939609 polymorphism, weight on average 3 - $4 \mathrm{~kg}$ more and have a 1.67-fold increased risk of obesity (Frayling et al., 2009). However, FTO functions are not yet fully described; an in vitro study showed that it acts as a co-activator of the C/EBP family of transcriptional regulators, which in conjunction with $P P A R G$ are necessary for adipocyte differentiation (Wu et al., 2010). In addition, it is expressed in proopiomelocortin-producing neurons participating in the satiety cycle (Tung et al., 2010). Accordingly, epidemiological studies support an association of the A allele with increased caloric intake (Speakman et al., 2008), and loss of overeating control (Tanofsky-Kraff et al., 2009). FTO rs9939609 was also associated with risk of obesity in a Mexican $(\mathrm{OR}=1.38, \mathrm{p}=$ $0.03)$ and Chinese populations $(\mathrm{OR}=1.29, \mathrm{p}=0.001)$ (Villalobos-Comparán et al., 2008; Xi et al., 2010)

The less studied $A D I P O Q$ gene encodes adiponectin, a hormone secreted by adipose tissue into plasma, where it binds with receptors in muscle and liver, and participates in glucose uptake and beta-oxidation of lipids. Adiponectin levels were associated with obesity and insulin resistance in an Italian population (Filippi et al., 2004). In a Mexican American population, ADIPOQ polymorphisms rs4632532 and $\mathrm{rs} 182052$ increased BMI $(\mathrm{p}=0.032$ and $\mathrm{p}=0.029$, respectively) (Richardson et al., 2006);. Polymorphism rs182052 was related with low expression levels of adiponectin, in a Chinese population (Ong et al., 2010).

In this study, we investigated the association between polymorphisms FTO rs9939609, PPARG2 rs1801282, and $A D I P O Q$ rs4632532 and rs182052 with obesity-related traits in a Mexican population with high prevalence of childhood obesity.

\section{Materials and Methods}

\section{Subjects}

Two hundred and fifteen Mexican mestizo children (108 males and 107 females, ranging from 6.1 to 12.3 years old), whose parents and grandparents were born in Mexico, were selected to participate in the study. Sampling was performed on ten public elementary schools from the bordering cities of Gómez Palacio and Lerdo, in the state of Durango, Mexico, between January and June 2012. The protocol was approved by the Ethics Committee of the Facultad de Medicina of the Universidad Autónoma de Coahuila, Mexico, and all parents signed an informed consent.

The BMI is an attempt to quantify the amount of tissue mass (muscle, fat, and bone) in an individual. It is defined as the body mass divided by the square of the body height, and is universally expressed in units of $\mathrm{kg} / \mathrm{m}^{2}$. The waist/height ratio is a better predictor of a person's metabolic risk (Browning et al., 2010) and is defined as waist circumference $(\mathrm{cm})$ divided by height $(\mathrm{cm})$. Triceps skin- fold thickness is measured in the right arm with Lange calipers. All children were assessed and measurements were recorded according to an established protocol (ShamahLevy and Villalpando-Hernández, 2007). The "overweight/obese" group was established using the age- and sex-specific BMI cutoff specified by the International Obesity Task Force (IOTF) (Cole et al., 2000) and by the World Health Organization (De Onis et al., 2007). Blood samples were drawn after overnight fasting. Total cholesterol, HDL (both by CHOD-PAP, Randox Laboratories Ltd. Ardmore, Crumlin, UK) and Triglyceride (Pointe Scientific Inc. Detroit, Michigan, US) levels were evaluated by enzymatic colorimetric methods. LDL levels were calculated using Friedewald's formula. Glucose levels were measured by Glucose Oxidase method (Randox Laboratories Ltd. Ardmore, Crumlin, UK). Plasma glucose levels were measured within 2 hours after the sample was obtained and plasma samples were stored at $-20^{\circ} \mathrm{C}$ until analysis for the other biochemical parameters.

Dietary information was obtained by a semi-quantitative food frequency questionnaire (FFQ) applied to mothers or caregivers by trained personnel. The questionnaire included 101 food items classified in 14 groups and was used by the National Institute of Public Health in The National Survey of Health and Nutrition 2006 (ENSANUT2006) (Shamah-Levy and Villalpando-Hernández, 2007). The interviewers asked about portions that were consumed by the children (times per week, times per day, and size) for each food item during the seven-day period prior to the interview. Dietary energy intake and source were calculated using the free specialized SNUT software (Rivera-Dommarco et al., 2001). The number of hours per week that children engaged in intense physical activity were also asked, and recorded as Metabolic Equivalent (MET)/hour (a unit of MET represents a multiple of the oxygen consumption when at rest, which corresponds to 3.5 $\mathrm{mL} \mathrm{O} \mathrm{Kg}^{-1} \mathrm{~min}^{-1}$. For example, if a person exercising expends $10 \mathrm{METs}$, he /she is using 10 times the amount of oxygen consumed when at rest) (Ridley et al., 2008; Morales-Ruán et al., 2009). Energy intake was assessed considering plausible intake levels according to the methodology used for ENSANUT2006 (Rodríguez-Ramírez et al., 2009). Children with reported energy intake above 5 standard deviations (outliers) or below $25 \%$ of the recommended caloric intake (extreme malnutrition) were excluded from the obesogenic environment analysis because these values are not biologically plausible $(n=164)$. Atypical food consumptions were manually reviewed and when a clear mistake was detected or if the value was not plausible, the participant was excluded.

\section{Genotyping assays}

Genomic DNA was isolated from peripheral white blood cells ( $3 \mathrm{~mL}$ blood in EDTA) using the salting out method (Lahiri and Nurnberger, 1991). Genotyping assays 
were performed with TaqMan probes in the ABI Prism 7900HT sequence Detection System (Applied Biosystems, Foster City, CA, USA) using the probes C_1129864_10 for $P P A R G$ rs 1801282 , C 3009062010 for FTO rs 9939609 , C_2412785_10 for $A D I P O Q$ rs4632532 and C 27807233 _ 10 for $A D I P O Q$ rs 182052 according to manufacturer's instructions (Applied Biosystems).

\section{Statistical analysis}

The quantitative variables were reported as medians and interquartile ranges. Allele and genotype frequencies were estimated by direct gene counting. The Hardy-Weinberg equilibrium was estimated using a Chi-square test. All the analyses were performed considering the cutoffs for obesity established by IOTF. Logistic regression models adjusted for age and gender were used to test associations of each genotype with overweight/obesity. We also analyzed the effect of polymorphisms on several anthropometric (waist circumference, arm circumference, triceps skinfold thickness, waist circumference/height ratio) and metabolic parameters (glucose, triglycerides, cholesterol, HDL, LDL) using linear regressions under an additive model adjusted by gender and age. All quantitative traits were logarithmically transformed before statistical analysis because some variables did not follow a normal distribution. Association analyses were performed using the STATA 11.1 software. Statistical significance was considered at $p$-values $<0.05$ for all comparisons.

\section{Results}

The prevalence of overweight/obesity in the 215 evaluated children was $43.72 \%$ and $39.07 \%$ based in the IOTF and WHO cutoffs, respectively (Table 1); no significant difference was observed in the association analysis using the different cutoffs. The obesogenic environment analysis showed that children consumed more fat and less protein than recommended (Casanueva and Kaufer, 2008),. Also, screen time was above the limit established by the American Association of Pediatrics (2h/day), and triceps skinfold thickness was higher than the normal for the median age (Casanueva et al., 2008). No significant associations were observed between obesogenic environment and obesity or related traits (data not shown).

Regarding the genetic background, we found a very high percentage of children with familiar history of obesity-related diseases such as diabetes mellitus (63.96\%) and hypertension $(59.90 \%)$. Some children had levels of biochemical parameters above the reference values (Interna-

Table 1 - General characteristics of the population studied.

\begin{tabular}{|c|c|}
\hline Variables & $\mathrm{n}(\%)$ \\
\hline \multicolumn{2}{|l|}{ Gender } \\
\hline & $108(50.23)$ \\
\hline & $107(49.77)$ \\
\hline \multicolumn{2}{|l|}{ IOTF cutoff } \\
\hline & Normal weight \\
\hline & Overweight/Obesity \\
\hline \multicolumn{2}{|l|}{ WHO cutoff } \\
\hline & Normal weight \\
\hline & Overweight/Obesity \\
\hline & Median (Min-Max) \\
\hline Age (years) & $10.4(6.10-12.30)$ \\
\hline \multicolumn{2}{|l|}{ Anthropometric } \\
\hline Waist circumference (cm) & $64.25(48.95-96.85)$ \\
\hline Arm circumference $(\mathrm{cm})$ & $21.95(13.50-35.50)$ \\
\hline Triceps (mm) & $15.00(5.50-28.00)$ \\
\hline Waist/height ratio & $0.46(0.35-0.63)$ \\
\hline \multicolumn{2}{|l|}{ Obesogenic Environment* } \\
\hline Energy intake (kJ/d) & $8837.62(4235.32-19608.62)$ \\
\hline Carbohydrates (\%) & $47.14(21.37-73.14)$ \\
\hline Protein $(\%)$ & $13.81(8.48-20.67)$ \\
\hline Fat $(\%)$ & $43.05(20.18-64.52)$ \\
\hline Physical activity (h/week) & $5(1-6)$ \\
\hline Screen hours (h/week) & $17(2-32)$ \\
\hline
\end{tabular}

${ }^{*} \mathrm{n}=164$ children included. IOTF: International Obesity Task Force; WHO: World Health Organization. 
tional Diabetes Federation) (Zimmet et al., 2007) (Table 2). The minor allele frequencies were 0.22 for $P P A R G$ rs 1801282, 0.35 for FTO rs9939609, 0.61 for ADIPOQ rs4632532 and 0.63 for $A D I P O Q$ rs182052, which are within range from those reported in other populations (Table 3). Genotype frequencies in all genes were in accordance with the Hardy-Weinberg equilibrium.

In respect to the association of genotypes with obesity, under an additive model, the OR was $1.25(\mathrm{CI}=0.73-$ 2.15) for $P P A R G$ rs $1801282,1.27(\mathrm{CI}=0.82-1.98)$ for FTO rs9939609, $1.47(\mathrm{CI}=0.78-2.74)$ for $A D I P O Q$ rs4632532 and $1.43(\mathrm{CI}=0.76-2.74)$ for $A D I P O Q$ rs182052. A risk tendency was observed, although these values were not significant (Table 3). The association, however, was assessed under the codominant, dominant and recessive models and the risk trend was preserved (data not shown). The analysis of genotypes with obesity-related characteristics found that $F T O$ was associated with BMI ( $\beta$ $=0.46, p=0.03)$, waist circumference $(\beta=0.03, p=0.02)$, triceps skinfold $(\beta=0.08, p=0.03)$ and waist/height ratio $(\beta=0.03, p=0.01)($ Table 4$)$. Additionally, FTO had an effect on total cholesterol $(\beta=0.06, p=0.02)$ and LDL $(\beta=$ $0.12, \mathrm{p}=0.01)$ levels, although the increase was modest; in contrast $A D I P O Q$ rs 4632532 and $P P A R G$ rs 1801282 were associated with a slight decrease in levels of HDL $(\beta=$
Table 2 - Biochemical parameters and hereditary backgrounds.

\begin{tabular}{lcc}
\hline $\begin{array}{l}\text { Biochemical parame- } \\
\text { ters }\end{array}$ & Median (Min-Max) & $\begin{array}{c}\text { \% Above reference } \\
\text { value* }\end{array}$ \\
\hline Glucose (mg/dL) & $79.87(58.34-113.07)$ & $5(2.33)$ \\
Cholesterol (mg/dL) & $148.49(84.80-353.70)$ & $25(11.63)$ \\
Triglycerides (mg/dL) & $78.29(26.58-221.60)$ & $16(7.44)$ \\
HDL (mg/dL) & $53.66(23.95-104.75)$ & $46(21.40)$ \\
LDL (mg/dL) & $74.21(24.38-299.34)$ & $14(6.51)$ \\
Familial history & $\mathbf{n}(\%)$ & \\
Diabetes mellitus & $126(63.96)$ & \\
Hypertension & $118(59.90)$ & \\
Dyslipidemia & $73(37.06)$ & \\
Cardiovascular & $42(21.32)$ & \\
\hline
\end{tabular}

* According to International Diabetes Federation (IDF)(Zimmet et al., 2007)

$-0.06, p=0.03)$ and triglycerides $(\beta=-0.11, p=0.04)$, respectively (Table 5).

\section{Discussion}

In this study, several risk factors of obesity were evaluated in a Mexican children population. The results revealed that genetic factors were associated with obesity

Table 3 - Comparison of association of FTO rs9939609, PPARG2 rs1801282, and ADIPOQ rs4632532 and rs182052 with obesity in different populations.

\begin{tabular}{|c|c|c|c|c|c|c|}
\hline Polymorphism & Allelic Frequency & Model & OR & IC $95 \%$ & Population & Reference \\
\hline \multicolumn{7}{|c|}{$P P A R G$ rs 1801282} \\
\hline & $\mathrm{G}=0.09$ & Additive & 2.36 & $1.10-5.05$ & Caucasian & $\begin{array}{l}\text { González-Sánchez, et } \\
\text { al., } 2002\end{array}$ \\
\hline & $\mathrm{G}=0.06$ & Dominant & 2.85 & $1.07-7.62$ & Caucasian & Morini, et al., 2008 \\
\hline & $\mathrm{G}=0.05$ & Dominant & 0.64 & $0.42-0.76$ & Chinese & Wang, et al., 2013 \\
\hline & $\mathrm{G}=0.11$ & Recessive & 3.2 & $1.2-12.9$ & Indian & Bhatt, et al., 2012 \\
\hline & $G=0.22$ & Additive & 1.25 & $0.73-2.15$ & Mexican - Mestizo & This study \\
\hline \multirow[t]{6}{*}{ FTO rs9939609 } & $\mathrm{A}=0.19$ & Additive & 1.41 & $1.15-1.76$ & Mexican - Mestizo & León-Mimila, et al., 2013 \\
\hline & $\mathrm{A}=0.20$ & Additive & 2.42 & $1.71-3.44$ & Mexican - Mestizo & $\begin{array}{c}\text { Villalobos-Camparán, et } \\
\text { al., } 2008\end{array}$ \\
\hline & $\mathrm{A}=0.12$ & Additive & 1.29 & $1.11-1.49$ & Chinese & $\mathrm{Xi}$, et al., 2010 \\
\hline & $\mathrm{A}=0.42$ & Additive & 1.27 & $1.20-1.34$ & Caucasian & Andreasen, et al., 2008 \\
\hline & $\mathrm{A}=0.59$ & Recessive & 1.97 & $1.29-3.00$ & Caucasian & Luczynski, et al., 2012 \\
\hline & $\mathrm{A}=\mathbf{0 . 3 5}$ & Additive & 1.27 & $0.82-1.98$ & Mexican - Mestizo & This study \\
\hline \multicolumn{7}{|l|}{ ADIPOQ } \\
\hline \multirow[t]{3}{*}{ rs 4632532} & $\mathrm{~T}=0.48$ & Codominant & Increase in BMI & & Mexican - American & Richardson, et al., 2005 \\
\hline & $\mathrm{T}=0.45$ & Codominant & Increase in BMI & & Hispano - American & Sutton, et al., 2005 \\
\hline & $\mathrm{T}=\mathbf{0 . 6 1}$ & Additive & 1.47 & $0.78-2.74$ & Mexican - Mestizo & This study \\
\hline \multirow[t]{4}{*}{ rs 182052} & $\mathrm{G}=0.37$ & Additive & 1.22 & $1.05-1.42$ & Afroamerican & Bostrom, et al., 2008 \\
\hline & $\mathrm{G}=0.48$ & Codominant & Increase in BMI & & Mexican - American & Richardson, et al., 2005 \\
\hline & $\mathrm{G}=0.44$ & Codominant & Increase in BMI & & Hispano - American & Sutton, et al., 2005 \\
\hline & $G=0.63$ & Additive & 1.43 & $0.76-2.74$ & Mexican - Mestizo & This study \\
\hline
\end{tabular}


Table 4 - Association of polymorphisms with obesity-related traits

\begin{tabular}{|c|c|c|c|c|}
\hline Measurements & FTO rs9939609 & PPARG rs 1801282 & $A D I P O Q$ rs 4632532 & $A D I P O Q$ rs 182052 \\
\hline & $\beta$ (CI 95\%, P-value) & $\beta$ (CI 95\%, P-value) & $\beta$ (CI 95\%, P-value) & $\beta(\mathrm{CI} 95 \%$, P-value $)$ \\
\hline \multirow[t]{2}{*}{ BMI } & 0.46 & -0.004 & 0.005 & -0.003 \\
\hline & $(0.005-0.08,0.03)$ & $(-0.05-0.04,0.87)$ & $(-0.03-0.04,0.75)$ & $(-0.04-0.03,0.84)$ \\
\hline \multirow[t]{2}{*}{ Waist circumference $(\mathrm{cm})$} & 0.03 & -0.01 & 0.004 & -0.001 \\
\hline & $(0.006-0.07,0.02)$ & $(-0.05-0.02,0.51)$ & $(-0.02-0.03,0.76)$ & $(0.03-0.02,0.90)$ \\
\hline \multirow[t]{2}{*}{ Arm circumference $(\mathrm{cm})$} & 0.03 & 0.002 & 0.002 & -0.005 \\
\hline & $(-0.002-0.07,0.07)$ & $(-0.04-0.04,0.92)$ & $(-0.03-0.03,0.87)$ & $(-0.03-0.02,0.37)$ \\
\hline \multirow[t]{2}{*}{ Triceps (mm) } & 0.08 & -0.03 & -0.02 & -0.03 \\
\hline & $(0.007-0.16,0.03)$ & $(-0.12-0.06,0.53)$ & $(-0.08-0.05,0.59)$ & $(-0.10-0.04,0.75)$ \\
\hline \multirow[t]{2}{*}{ Waist/height ratio } & 0.03 & -0.01 & -0.002 & -0.003 \\
\hline & $(0.007-0.06,0.01)$ & $(-0.04-0.02,0.54)$ & $(-0.02-0.02,0.85)$ & $(-0.03-0.02,0.76)$ \\
\hline
\end{tabular}

Linear regression was used to compare obesity measurements by genotype, using additive model adjusted for age and gender. Significant associations ( $\mathrm{p}$ $<0.05$ ) are indicated in bold. BMI: body mass index.

Table 5 - Association of polymorphisms with biochemical parameters

\begin{tabular}{|c|c|c|c|c|}
\hline Biochemical & FTO rs9939609 & $P P A R G$ rs 1801282 & $A D I P O Q$ rs 4632532 & $A D I P O Q$ rs 182052 \\
\hline Parameter & $\beta$ (CI 95\%, P-value) & $\beta$ (CI 95\%, P-value) & $\beta$ (CI 95\%, P-value $)$ & $\beta$ (CI 95\%, P-value $)$ \\
\hline \multirow[t]{2}{*}{ Glucose } & 0.01 & -0.02 & 0.003 & 0.001 \\
\hline & $(-0.01-0.03,0.36)$ & $(-0.05-0.006,0.11)$ & $(-0.02-0.02,0.75)$ & $(-0.02-0.02,0.95)$ \\
\hline \multirow[t]{2}{*}{ Cholesterol } & 0.06 & 0.01 & -0.01 & -0.006 \\
\hline & $(001-0.11,0.02)$ & $(-0.05-0.07,0.72)$ & $(-0.05-0.03,0.64)$ & $(-0.05-0.04,0.77)$ \\
\hline \multirow[t]{2}{*}{ Triglycerides } & 0.07 & -0.11 & 0.04 & 0.04 \\
\hline & $(-0.02-0.15,0.14)$ & $(-0.22--0.003,0.04)$ & $(-0.04-0.11,0.30)$ & $(-0.04-0.12,0.30)$ \\
\hline \multirow[t]{2}{*}{$\mathrm{HDL}$} & -0.02 & 0.01 & -0.06 & -0.05 \\
\hline & $(-0.09-0.05,0.56)$ & $(-0.07-0.09,0.78)$ & $(-0.12--0.007,0.03)$ & $(-0.11-0.01,0.12)$ \\
\hline \multirow[t]{2}{*}{ LDL } & 0.12 & 0.04 & 0.03 & 0.02 \\
\hline & $(0.03-0.22,0.01)$ & $(-0.07-0.16,0.47)$ & $(-0.05-0.11,0.43)$ & $(-0.06-0.10,0.63)$ \\
\hline
\end{tabular}

Linear regression was used to compare biochemical measurements by genotype, using additive model adjusted for age, gender and body mass index. Significant associations $(\mathrm{p}<0.05)$ are indicated in bold.

related traits, while the obesogenic environment had no effect. The frequency of risk genotypes in FTO rs9939609, $P P A R G$ rs 1801282 , and $A D I P O Q$ rs4632532 and rs 182052 was different from what has been reported in other populations. This was expected as a result, since studies show that there is variability in frequencies of polymorphisms in different populations of the same ethnicity (Table 3 ). In regard to the association of these genes with obesity, most studies report OR's in the range of 1.2 to 2, similar to our results, indicating that these genes are of low penetrance and their contribution to the development of obesity is small. However, the presence of several genetic factors together with other factors could have a significant effect.

The presence of polymorphism FTO rs9939609 was associated with an increment in BMI, waist circumference and waist/height ratio. Waist/height ratio measures the abdominal fat in any gender or age and is a better metabolic risk predictor than BMI (Browning et al., 2010; Kodama et al., 2012). This result is in agreement with other studies in different populations (León-Mimila et al., 2013; Luczynski et al., 2012; Villalobos-Comparán et al., 2008; Xi et al., 2010). We also found that the A allele increases the risk of alterations in the lipid profile (cholesterol and HDL levels), as reported by other groups (Villalobos-Comparán et al., 2008; Mascarenhas-Melo et al., 2013). This supports the suggested activity of FTO protein, in conjunction with C/EBP, as a co-activator of PPAR gamma, which is involved in adipocyte functions, such as lipid metabolism and differentiation (Wu et al., 2010).

The polymorphism PPARG Pro12Ala (rs1801282) has been studied in different populations with contradictory results; in some studies Ala allele was associated with obesity (Bhatt et al., 2012; Morini et al., 2008), whereas in a Chinese population, it was reported as a protecting factor 
(Wang et al., 2013). In our study, we did not find an association under any model. However, this polymorphism showed a negative association with triglycerides level $(\beta=$ $-0.11, \mathrm{p}=0.04)$. This can be supported by in vitro evidence, which shows that allele Ala presents less affinity to DNA, and as a result, the ability to induce lipogenesis is decreased (Larsen et al., 2003). The different results reported for PPARG rs1801282 may be due to PPARG being a transcription factor that responds to the environment (high fatty acids diet) and shows epistasis with other polymorphisms in the same gene (rs2938392, rs1175542, rs1175544) and other genes (ADB3R). Therefore, specific features of the obesogenic environment may influence associations according to the population analyzed.

ADIPOQ rs4632532 showed an association with decreased HDL levels. The polymorphisms evaluated in this study are associated with obesity in Afro-Americans (Bostrom et al., 2008) and with increased BMI, waist circumference, fasting insulin levels and skin fold thickness in Mexicans living in USA (Richardson et al., 2006; Sutton et al., 2005). However, those studies did not find an association with HDL levels. Adiponectin participates in the betaoxidation of fatty acids (Kadowaki and Yamauchi, 2005), so it is possible that the polymorphic gene impacts the transport of fatty acids (in HDL) into plasma. Accordingly, a positive correlation between HDL and adiponectin levels has been reported elsewhere (Mascarenhas-Melo et al., 2013). Although we did not measure plasma adiponectin, these studies support our results.

In addition to genetic factors, the obesogenic environment including diet, physical activity and screen time was evaluated, but no association was found between environmental factors and obesity or gain in anthropometric measurements. Similar results were found in the National Survey 2006 (Flores et al., 2009). This study presents inaccuracies in diet records of both obese and non-obese groups. Therefore, energy intake could have been wrongly associated with obesity. This imprecision is frequently caused by the use of questionnaires as tools for diet intake assessment. The use of dietary diaries could overcome the problem; however, that method becomes impractical when large populations are surveyed.

The findings of our study are important because there are only two other studies that show association of FTO rs9930609 with obesity or obesity-related traits and modified lipid profile in a Mexican population. In addition, the polymorphisms of PPARG rs1801282 and ADIPOQ rs4632532 were not assessed in those previous studies. However, limitations in our study include a small sample size and difficulty determining the obesogenic environment factors.

In conclusion, this study analyzed environment and genetic aspects of obesity and found significant associations between PPARG rs1801282 and triglycerides levels,
ADIPOQ rs4632532 and HDL levels, and FTO rs9939609 with cholesterol, LDL and anthropometric measurements.

\section{Acknowledgments}

This study was supported by scholarship CVU249976 (CM). We thank L.N. Lucero Torres Nava and M.C. Alejandra Mendez Hernandez for technical assistance, and Dr. Ezequiel Fuentes Pananá, for critical reading of the manuscript

\section{References}

Bhatt S P, Misra A, Sharma M, Luthra K, Guleria R, Pandey RM and Vikram N K (2012) Ala/Ala genotype of Pro12Ala polymorphism in the peroxisome proliferator-activated receptor- $\gamma 2$ gene is associated with obesity and insulin resistance in Asian Indians. Diabetes Technol Ther 14:828-834.

Bostrom MA, Freedman BI, Langefeld CD, Liu L, Hicks PJ and Bowden DW (2008) Association of adiponectin gene polymorphisms with type 2 diabetes in an African American population enriched for nephropathy. Diabetes 58:499-504.

Browning LM, Hsieh SD and Ashwell M (2010) A systematic review of waist-to-height ratio as a screening tool for the prediction of cardiovascular disease and diabetes: 05 could be a suitable global boundary value. Nutri Res Rev 23:247-269.

Casanueva E and Kaufer MPAB (2008) Nutriología Médica. 3rd edition. Panamerica Press, México, DF, p 78-85.

Cole TJ, Bellizzi MC, Flegal KM and Dietz WH (2000) Establishing a standard definition for child overweight and obesity worldwide: International survey. BMJ 320:1-6.

De Onis M, Onyango AW, Borghi E, Siyam A, Nishida C and Siekmann J (2007) Development of a WHO growth reference for school children and adolescents. Bull WHO 85:660-667.

Filippi E, Sentinelli F, Trischitta V, Romeo S, Arca M, Leonetti F and Baroni M G (2004) Association of the human adiponectin gene and insulin resistance. Eur J Hum Genet 12:199-205.

Flores M, Macías N, Rivera M, Barquera S, Hernández L, García-Guerra A and Rivera JA (2009) Energy and nutrient intake among Mexican school-aged children, Mexican National Health and Nutrition Survey 2006. Salud Púb México 51(Suppl 4):S540-S550.

Frayling TM, Timpson NJ, Weedon MN, Freathy RM, Lindgren CM, Perry JRB and McCarthy MI (2009) A common variant in the FTO gene is associated with body mass index and predisposes to childhood and adult obesity. Science 316:889894.

Ghoussaini M, Meyre D, Lobbens S, Charpentier G, Clément K, Charles M-A and Froguel P (2005) Implication of the Pro12Ala polymorphism of the PPAR-gamma 2 gene in type 2 diabetes and obesity in the French population. BMC Med Genet 6:e11.

González-Sánchez JL, Serrano Ríos M, Fernández Perez C, Laakso M and Martínez Larrad, MT (2002) Effect of the Pro12Ala polymorphism of the peroxisome proliferatoractivated receptor gamma-2 gene on adiposity, insulin sensitivity and lipid profile in the Spanish population. Eur J Endocrinol 147:495-501. 
He W (2009) PPAR $\gamma 2$ polymorphism and human health. PPAR Res 2009:e849538.

Kadowaki T and Yamauchi T (2005) Adiponectin and adiponectin receptors. Endocr Rev 26:439-451.

Kodama S, Horikawa C, Fujihara K, Heianza Y, Hirasawa R, Yachi Y and Sone H (2012) Comparisons of the strength of associations with future type 2 diabetes risk among anthropometric obesity indicators, including waist-to-height ratio: A meta-analysis. Am J Epidemiol 176:959-969.

Lahiri DK and Nurnberger JI (1991) A rapid non-enzymatic method for the preparation of HMW DNA from blood for RFLP studies. Nucleic Acids Res 19:544-548.

Larsen TM, Toubro S and Astrup A (2003) PPARgamma agonists in the treatment of type II diabetes: Is increased fatness commensurate with long-term efficacy? Int J Obes Relat Metab Disord 27:147-161.

León-Mimila P, Villamil-Ramírez H, Villalobos-Comparán M, Villarreal-Molina T, Romero-Hidalgo S, López-Contreras B, Gutiérrez-Vidal R, Vega-Badillo J, Jacobo-Albavera L, Posadas-Romeros C, et al. (2013) Contribution of common genetic variants to obesity and obesity-related traits in Mexican children and adults. PLoS One 8:e70640.

Luczynski W, Zalewski G and Bossowski A (2012) The association of the FTO rs9939609 polymorphism with obesity and metabolic risk factors for cardiovascular diseases in Polish children. J Physiol Pharmacol 63:241-248.

Mascarenhas-Melo F, Sereno J, Teixeira-Lemos E, Marado D, Palavra F, Pinto R, Rocha-Pereira P, Teixeira F and Reis F (2013) Implication of low HDL-c levels in patients with average LDL-c levels: A focus on oxidized LDL, large HDL subpopulation, and adiponectin. Mediators Inflamm 2013:e612038.

Morales-Ruán MDC, Hernández-Prado B, Gómez-Acosta LM, Shamah-Levy T and Cuevas-Nasu, L (2009) Obesity, overweight, screen time and physical activity in Mexican adolescents. Salud Púb México 51(Suppl 4-1):S613-S620.

Morini E, Tassi V, Capponi D, Ludovico O, Dallapiccola B, Trischitta V and Prudente S (2008) Interaction between PPARgamma2 variants and gender on the modulation of body weight. Obesity 16:1467-1470.

Ong KL, Li M, Tso AWK, Xu A, Cherny SS, Sham PC and Lam KSL (2010) Association of genetic variants in the adiponectin gene with adiponectin level and hypertension in Hong Kong Chinese. Eur J Endocrinol 163:251-257.

Richardson DK, Schneider J, Fourcaudot MJ, Rodriguez LM, Arya R, Dyer TD, Almasy L, Blangero J, Stern MP, Defronzo RA, et al. (2006) Association between variants in the genes for adiponectin and its receptors with insulin resistance syndrome (IRS)-related phenotypes in Mexican Americans. Diabetologia 49:2317-2328.

Ridley K, Ainsworth BE and Olds TS (2008) Development of a compendium of energy expenditures for youth. Int J Behav Nutr Phys Act 5:e45.

Rivera-Dommarco J, Shamah-Levy T, Villalpando-Hernández S, González de Cossío T and Hernández Prado B SJ (2001). Encuesta Nacional de Nutrición 1999. Estado Nutricio de niños y mujeres de México. Cuernavaca, Morelos, p 188190.
Rivero-Vázquez S (2013) Encuesta Nacional de Salud y Nutrición2012. Durango (Vol. 2). Cuernavaca, Morelos, p 78-82.

Rodríguez-Ramírez S, Mundo-Rosas V, Jiménez-Aguilar A and Shamah-Levy T (2009) Methodology for the analysis of dietary data from the Mexican National Health and Nutrition Survey 2006. Salud Públ México 51(Suppl 4):S523-S529.

Shamah-Levy T and Villalpando-Hernández SRDJ (2007) Resultados de Nutrición de la ENSANUT 2006. Cuernavaca, México, p 44-53.

Silva-Zolezzi I, Hidalgo-Miranda A, Estrada-Gil J, FernandezLopez JC, Uribe-Figueroa L, Contreras A and Jimenez-Sanchez G (2009) Analysis of genomic diversity in Mexican Mestizo populations to develop genomic medicine in Mexico. Proc Natl Acad Sci U S A 106:8611-8616.

Speakman JR, Rance KA and Johnstone AM (2008) Polymorphisms of the FTO gene are associated with variation in energy intake, but not energy expenditure. Obesity 16:19611965.

Sutton BS, Weinert S, Langefeld CD, Williams AH, Campbell JK, Saad MF and Bowden DW (2005) Genetic analysis of adiponectin and obesity in Hispanic families: The IRAS Family Study. Hum Genet 117:107-118.

Tanofsky-Kraff M, Han JC, Anandalingam K, Shomaker LB, Columbo KM, Wolkoff LE and Yanovski JA (2009) The FTO gene rs9939609 obesity-risk allele and loss of control over. Am J Clin Nutr 90:1483-1488.

Tung Y-CL, Ayuso E, Shan X, Bosch F, O'Rahilly S, Coll AP and Yeo GSH (2010) Hypothalamic-specific manipulation of FTO, the ortholog of the human obesity gene FTO, affects food intake in rats. PloS One 5:e8771.

Villalobos-Comparán M, Teresa Flores-Dorantes M, Teresa Villarreal-Molina M, Rodríguez-Cruz M, García-Ulloa AC, Robles L, Huertas-Vázquez A, Saucedo-Villarreal N, López-Alarcón M, Sánchez-Muñoz F, et al. (2008) The FTO gene is associated with adulthood obesity in the Mexican population. Obesity 16:2296-2301.

Wang X, Liu J, Ouyang Y, Fang M, Gao H and Liu L (2013) The association between the Pro12Ala variant in the PPAR $\gamma 2$ gene and type 2 diabetes mellitus and obesity in a Chinese population. PLoS One 8:e71985.

Wu Q, Saunders R, Szkudlarek-Mikho M, La Serna ID and Chin $\mathrm{K}-\mathrm{V}$ (2010). The obesity-associated Fto gene is a transcriptional coactivator. Biochem Biophys Res Commun 401:390-395.

Xi B, Shen Y, Zhang M, Liu X, Zhao X, Wu L and Wang X (2010) The common rs9939609 variant of the fat mass and obesity-associated gene is associated with obesity risk in children and adolescents of Beijing, China. BMC Med Genet 11:e107.

Zimmet P, Alberti G, Kaufman F, Tajima N, Silink M, Arslanian $S$ and Caprio S (2007) The metabolic syndrome in children and adolescents-an IDF consensus report. Diabetes Voice 52:29-32.

Associate Editor: Mara H. Hutz

License information: This is an open-access article distributed under the terms of the Creative Commons Attribution License (type CC-BY), which permits unrestricted use, distribution and reproduction in any medium, provided the original article is properly cited. 